Résumés des conférences et travaux

\title{
Histoire monétaire et financière du monde grec
}

Conférences de l'année 2011-2012

François de Callataÿ

\section{(2) OpenEdition}

1 Journals

Édition électronique

URL : https://journals.openedition.org/ashp/1456

DOI : 10.4000/ashp. 1456

ISSN : 1969-6310

Éditeur

Publications de l'École Pratique des Hautes Études

\section{Édition imprimée}

Date de publication : 1 septembre 2013

Pagination : 55

ISSN : 0766-0677

\section{Référence électronique}

François de Callataÿ, "Histoire monétaire et financière du monde grec », Annuaire de l'École pratique des hautes études (EPHE), Section des sciences historiques et philologiques [En ligne], 144 | 2013, mis en ligne le 22 octobre 2014, consulté le 05 novembre 2021. URL : http://journals.openedition.org/ashp/ 1456 ; DOI : https://doi.org/10.4000/ashp.1456 


\title{
HISTOIRE MONÉTAIRE ET FINANCIĖRE DU MONDE GREC
}

\author{
Directeur d'études : M. François DE Callatä̈
}

Programme de l'année 2011-2012 : I. Numismatique grecque : actualités. - II. Recherches en cours.

L'année académique 2011-2012 a été atypique en ce que le directeur d'études n'a pas, comme les autres années, commenté une série de recherches en cours mais a choisi de présenter de façon approfondie l'ensemble des notions qui fondent les études de numismatique antique. C'était là à la fois permettre à ses auditeurs, dont certains le suivent depuis près de quinze ans à présent, d'avoir l'opportunité de retourner aux fondements des méthodes et des outils qui sont d'application usuelle dans les recherches dont il est question à l'occasion de cette conférence, et aussi de réactiver le projet, trop longtemps laissé de côté, de publier un manuel méthodologique de numismatique grecque.

Les conférences de l'année ont abordé les thèmes suivants : réunion du matériel nécessaire à une étude de coins, avec une insistance particulière sur les bases de données en ligne telles que Coinarchives, ACsearch et Wildwinds, réalisation d'une étude de coins, étude des poids, des trésors et de la composition métallique. À chaque fois, la volonté a été de se montrer pratique, en renseignant la meilleure méthode telle qu'elle se pratique aujourd'hui tout en attirant l'attention sur les pièges et les difficultés de l'interprétation et de la mise en œuvre du matériel monétaire. 